\title{
ANALISIS PENGARUH WAKTU PERLAKUKAN PANAS TERHADAP NILAI KEKERASAN KARBURASI BAJA KARBON RENDAH
}

\author{
Yeni Yusuf Tonglolangi \\ Fakultas Teknik, Program Studi Teknik Mesin, UKI Toraja \\ email: yeni.y.tonglolangi@gmail.com
}

\begin{abstract}
Abstrak
Logam mempunyai peran aktif dalam kehidupan manusia, oleh karena itu dilakukan usaha untuk memperbaiki sifat-sifat dari logam tersebut yaitu merubah sifat mekanis dan sifat fisiknya. Penelitian ini bertujuan untuk menganalisis pengaruh waktu perlakuan panas terhadap kekerasan baja karbon rendah.Salah satu cara untuk meningkatkan nilai kekerasannya adalah dengan melakukan proses karburasi, yaitu proses perlakuan panas untuk mendapatkan kulit logam yang lebih keras dari sebelumnya.

Dari hasil penelitian diperoleh dari variasi waktu perlakukan panas 30 menit, 45 menit, 60 menit dan 75 menit dengan media pendingin air garam, diperoleh nilai kekerasan tertinggi pada waktu pemanasan 75 menit yaitu $69,67 \mathrm{~kg} / \mathrm{mm}^{2}$.
\end{abstract}

Kata Kunci: Baja Karbon, waktu perlakukan panas, karburasidan nilai kekerasan.

\section{PENDAhUluan}

Kebutuhan manusia akan logam semakin meningkat, oleh karena itu diperlukan usaha untuk memperbaiki kualitasnya, salah satunya dengan memperbaiki sifat bahan.

Baja karbon mendapat prioritas utama dalam pemilihan bahan karena mudah diperoleh, mudah dibentuk dan harganya relatif murah. Namun demikian, masih perlu memodifikasi atau memperbaiki sifatnya seperti kekerasan pada permukaan dan tahan aus akibat gesekan. Oleh karena itu maka perlu diadakan proses perlakuan panas guna menambah kekerasan bahan.Perlakuan panas adalah suatu perlakuan (treatment) yang diterapkan pada logam agar diperoleh sifat-sifat yang diinginkan. Dengan cara pemanasan dan pendinginan dengan kecepatan tertentu yang dilakukan terhadap logam dalam keadaan fase padat sebagai upaya untuk memperoleh sifat-sifat tertentu dari logam.

Salah satu cara untuk meningkatkan nilai kekerasan adalah dengan menggunakan proses karburasi. Karburasi adalah salah satu proses perlakuan panas untuk mendapatkan kulit yang lebih keras dari sebelumnya.

\section{KAJIAN LITERATUR}

\subsection{Baja Karbon}

Baja merupakan paduan yang sebagian besar terdiri dari unsur besi dan karbon 0,2\%-2,1\% . Selain itu juga mengandung unsur-unsur lain seperti sulfur (S), fosfor $(\mathrm{P})$, silikon ( $\mathrm{Si}$ ), mangan $(\mathrm{Mn})$, dan sebagainya. Namuñ unsur-unsur ini hanya dalam presentase kecil.Sifat baja karbon dipengaruhi oleh presentase karbon dan struktur mikro. Sedangkan struktur mikro pada baja karbon dipengaruhi oleh perlakuan panas dan komposisi baja.

Komposisi baja dapat dikelompokkan sebagai berikut:

1. Baja karbon rendah 
Baja karbon rendah (low carbon steel) mengandung karbon dalam campuran baja kurang dari 0,3\%C. Baja ini tidak dapat dikeraskan karena kandungan karbonnya tidak cukup untuk membentuk struktur martensit.

2. Baja karbon sedang

Baja karbon sedang (medium carbon steel) mengandung karbon 0,3\% $-0,6 \% \mathrm{C}$. Baja ini dapat dikeraskan melalui proses perlakuan panas yang sesuai. Baja ini lebih keras serta lebih kuat dibandingkan dengan baja karbon rendah.

3. Baja karbon tinggi

Baja karbon tinggi memiliki kandungan karbon 0,6\% C - 1,5\% Canmemiliki kekerasan yang lebih tinggi, namun keuletannya lebih rendah. Berkebalikan dengan baja karbon rendah, pengerasan dengan perlakuan panas pada baja karbon tinggi tidak memberikan hasil yang optimal karena terlalu banyaknya martensit, sehingga membuat baja menjadi getas.

\subsection{Sifat-sifat Logam}

Logam mempunyai beberapa sifat antara lain: sifat mekanis, sifat fisika, sifat kimia, dan sifat pengerjaan. Sifat mekanis adalah kemampuan suatu logam untuk menahan beban yang diberikan pada logam tersebut. Yang termasuk sifat mekanis pada logam, antara lain: kekuatan bahan (strength), kekerasan elastisitas, kekakuan, plastisitas, kelelahan bahan, sifat fisika, sifat kimia, dan sifat pengerjaan.

Kekuatan (strength) adalah kemampuan material untuk menahan tegangan tanpa kerusakan. Beberapa material seperti baja struktur, besi tempa, alumunium, dan tembaga mempunyai kekuatan tarik dan tekan yang hampir sama. Ukuran kekuatan bahan adalah tegangan maksimumnya, atau gaya terbesar persatuan luas yang dapat ditahan bahan tanpa patah. Untuk mengetahui kekuatan suatu material dapat dilakukan dengan pengujian tarik, tekan, atau geser.

Kekerasan (hardness) adalah ketahanan suatu bahan untuk menahan pembebanan yang dapat berupa goresan atau penekanan. Untuk mengetahui kekerasan suatu material digunakan Uji Brinell. Kekakuan adalah ukuran kemampuan suatu bahan untuk menahan perubahan bentuk atau deformasi setelah diberi beban. Kelelahan bahan adalah kemampuan suatu bahan untuk menerima beban yang berganti-ganti dengan tegangan maksimum diberikan pada setiap pembebanan.

Elastisitasadalah kemampuan suatu bahan untuk kembali ke bentuk semula setelah menerima beban yang mengakibatkan perubahan bentuk. Elastisitas ini penting pada semua struktur yang mengalami beban yang berubah-ubah terlebih pada alat-alat dan mesin-mesin presisi.

Plastisitas adalah kemampuan suatu bahan padat untuk mengalami perubahan bentuk tetap tanpa ada kerusakan. Sifat fisika adalah karakteristik suatu bahan ketika mengalami peristiwa fisika seperti adanya pengaruh panas atau listrik. Yang termasuk sifat-sifat fisika adalah sebagai berikut: titik lebur, kepadatan, daya hantar panas, dan daya hantar listrik.

\subsection{Proses Perlakuan Panas}

Perlakuan panas adalah suatu metoda yang digunakan untuk mengubah sifat fisik atau struktur mikro suatu logam melalui proses pemanasan dan pengaturan kecepatan pendinginan dengan atau tanpa mengubah komposisi kimia material tersebut.

Struktur logam dapat mengalami perubahan melalui perlakuan panas sehingga mempengaruhi sifatsifat logam tersebut seperti perubahan besar butir, ketangguhan, kekerasan permukaan, dan lainlain. Perlakuan panas pada suatu logam dengan temperatur di atas temperatur kritis di mana mulai terjadi perubahan struktur ferit menjadi ausenit, lalu temperatur pemanasan di tahan beberapa saat sebelum dilakukan pendinginan melalui proses pencelupan ataupun dengan udara. 


\subsection{Pengujian Nilai Kekerasan}

Pengujian kekerasan dilakukan untuk mengetahui sejauh mana logam mempunyai ketahanan terhadap deformasi plastis akibat penetrasi pada permukaannya. Ada 3 metode yang umum dilakukan dalam pengujian kekerasan, yaitu:

a. Cara Goresan

Pengujian ini dilakukan dengan cara saling menggoreskan duah buah logam yang berbeda. Besarnya nilai kekerasan ini diukur dengan menggunakan skala Mohs, dimana skala ini terdiri dari 10 standar angka yang menandakan kemampuan suatu logam uji untuk digores.

b. Cara Dinamis

Prinsip kerja dari cara ini adalah dengan menjatuhkan suatu benda penguji keatas permukaan logam uji dari ketinggian tertentu yang akan meninggalkan lekukan ketika benda yang dijatuhkan itu memantul dari permukaanb logam yang diuji. Kekerasan suatu logam dapat diukur melalui alat Sholesroskopshare dari ketinggian lekukan dan pantulan pada permukaan logam tersebut.

c. Cara penekanan

Benda uji diberikan beban secara teratur melalui alat uji sehingga meninggalkan jejak pada permukaan logam yang diuji. Jejak inilah yang kemudian kita teliti untuk menghitung besarnya nilai kekerasan logam tersebut. Pengujian kekerasan dengan cara penekanan ini dapat dilakukan dengan 3 cara, yaitu: cara Vickers, cara Rockwell dan cara Brinell.

Pada penelitian ini, dilakukan uji kekerasan dengan cara Rockwell.Pengujian kekerasan dengan menggunakan metode Rockwell bertujuanuntuk menentukan kekerasan suatu material dalam bentuk daya tahan terhadap penekan atau indentor berupa bola baja ataupun kerucut intan yang ditekankan pada permukaan material uji. Nilai kekerasan dari metode Rockwell diperoleh berdasarkan bekas kedalaman penekan atau indentor. Makin keras material yang diuji maka semakin dangkal kedalaman yang terbentuk, sebaliknya semakin dalam masuknya penekan pada material menunjukkan material yang diuji memiliki nilai kekerasan yang rendah.

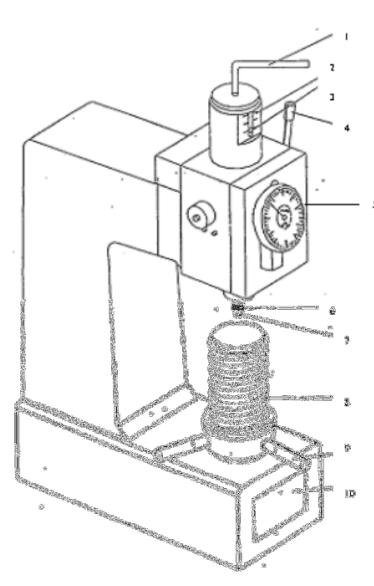

1. Wrench to select tested loads (kunci).

2. Tested loads mobile selector.

3. Loads scale.

4. Test Lever (handle).

5. Scale Indicator Pointer.

- Small pointer.

- Larger pointer.

- Red dot.

- Outer rings.

6. Ring nuts to fix the penetrator.

7. Penetrator (indentor)

8. Anvil (dudukan).

9. Anvil holder screw (capstan).

10. Handwheel to regulate therising screw

Gambar 2.1 Alat Uji Kekerasan Rockwell Sumber :http://cybersatu.blogspot.com/2011/05/pengujian-kekerasan-rockwell.html

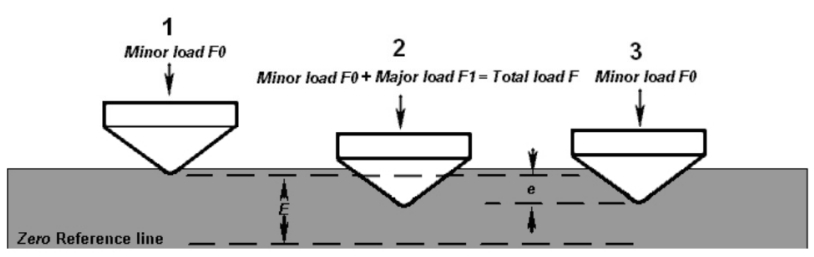




\section{Gambar 2.2 Prinsip Kerja Metode Kekerasan Rockwell Sumber :http://cybersatu.blogspot.com/2011/05/pengujian-kekerasan-rockwell.html}

\subsection{Jenis-jenis Pengerasan}

\subsubsection{Pengerasan Induksi}

Merupakan suatu metode pengerasan permukaan menggunakan arus induksi bolak-balik dengan frekuensi tinggi. Arus yang mengalir akan menimbulkan induksi pada permukaan baja, sehingga menimbulkan reaksi panas. Panas yang ditimbulkan oleh tegangan induksi kemudian diquencing menggunakan air dingin untuk membuang kerak-kerak yang terbentuk akibat adanya tegangan induksi pada permukaan baja.

\subsubsection{Pengerasan Permukaan}

1. Karburasi

Besi dipanaskan dalam lingkungan yang mengandung karbon baik dalam bentuk padat, cair ataupun gas.

2. Karbonitriding

Cara pengerasan permukaan, dimana baja dipanaskan diatas suhu kritis dalam lingkungan gas dan terjadi penyebaran karbon nitrogen.

3. Cyanding

Proses ini terjadi absorbsi karbon dan nitrogen untuk memperoleh permukaan yang keras pada baja karbon rendah yang sulit dikeraskan.

4. Nitriding

Disini digunakan bahan dan suhu yang berlainan. Logam dipanaskan sampai $\left(510^{\circ} \mathrm{C}\right)$ dalam lingkungan gas ammonia selama beberapa menit.

Pada penelitian ini digunakan jenis pengerasan karburasi dengan media karburasi Barium Karbonat dengan komposisi $20 \% \mathrm{BaCO}_{3}$ dan arang kayu cemara $80 \%$ dan suhu pemanasan konstan $800^{\circ} \mathrm{C}$.

\section{METODE PENELITIAN}

Pada penelitian digunakan baja karbon rendah yang berbentuk dilinder dengan diameter $12 \mathrm{~mm}$ dan panjang $12 \mathrm{~mm}$.

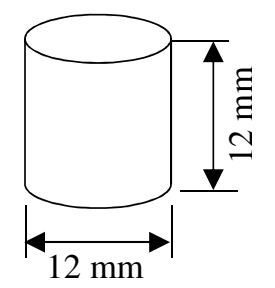

Gambar 3.1 Spesimen Benda Kerja

1. Pengujian kekerasan yang dilakukan dalam penelitian ini adalah metode Rockwell skala $\mathrm{C}$

2. Material yang digunakan adalah baja karbon rendah.

3. Media yang di gunakan dalam penelitian ini ialah Barium Karbonat dengan $20 \% \mathrm{BaCO}_{3}$ dan arang kayu cemara $80 \%$ dengan suhu pemanasan $800^{\circ} \mathrm{C}$.

4. Waktu tahan 30 menit, 45 menit, 60 menit, 75 menit.

5. Media pendingin yang digunakan adalah air garam. 


\section{HASIL DAN PEMBAHASAN}

\subsection{Hasil Penelitian}

Tabel 4.1. Data Pengamatan Nilai Kekerasan Baja Karbon Rendah untuk Kondisi Normal

\begin{tabular}{|c|c|c|c|c|c|c|}
\hline $\begin{array}{c}\text { Suhu/ } \\
\text { waktu }\end{array}$ & Spesimen & $\begin{array}{c}\text { Beban } \\
(\mathrm{kg})\end{array}$ & $\begin{array}{c}\mathrm{D} \\
(\mathrm{mm})\end{array}$ & $\begin{array}{c}\mathrm{HRB}_{1} \\
\left(\mathrm{~kg} / \mathrm{mm}^{2}\right)\end{array}$ & $\begin{array}{c}\mathrm{HRB}_{2} \\
\left(\mathrm{~kg} / \mathrm{mm}^{2}\right)\end{array}$ & $\begin{array}{c}\mathrm{HRB} \\
\text { rata-rata } \\
\left(\mathrm{kg} / \mathrm{mm}^{2}\right)\end{array}$ \\
\hline \multirow{2}{*}{ Normal } & 1 & 100 & 1,588 & 28 & 55 & \multirow{2}{*}{55,00} \\
\cline { 2 - 6 } & 2 & 100 & 1,588 & 24 & 54 & \multirow{2}{*}{} \\
\cline { 2 - 6 } & 3 & 100 & 1,588 & 26 & 56 & \\
\hline
\end{tabular}

Tabel 4.1. Data Pengamatan Nilai Kekerasan Baja Karbon Rendah dengan Komposisi Media Arang Kayu Cemara dan Barium Karbonat $\left(\mathrm{BaCO}_{3}\right)$ Melalui Proses Karburasi dengan Pendinginan Air Garam.

\begin{tabular}{|c|c|c|c|c|c|c|}
\hline $\begin{array}{l}\text { Suhu/ } \\
\text { waktu }\end{array}$ & Spesimen & $\begin{array}{c}\text { Beban } \\
(\mathrm{kg})\end{array}$ & $\underset{(\mathrm{mm})}{\mathrm{D}}$ & $\underset{\left(\mathrm{kg} / \mathrm{mm}^{2}\right)}{\mathrm{HRB}_{1}}$ & $\underset{\left(\mathrm{kg} / \mathrm{mm}^{2}\right)}{\mathrm{HRB}_{2}}$ & $\begin{array}{c}\text { HRB } \\
\text { rata-rata } \\
\left(\mathrm{kg} / \mathrm{mm}^{2}\right)\end{array}$ \\
\hline \multirow{3}{*}{$\begin{array}{c}800^{\circ} \mathrm{C} / \\
30 \text { menit }\end{array}$} & 1 & 100 & 1,588 & 36 & 64 & \multirow{3}{*}{63,33} \\
\hline & 2 & 100 & 1,588 & 31 & 60 & \\
\hline & 3 & 100 & 1,588 & 38 & 66 & \\
\hline \multirow{3}{*}{$\begin{array}{c}800^{\circ} \mathrm{Cl} \\
45 \text { menit }\end{array}$} & 1 & 100 & 1,588 & 40 & 69 & \multirow{3}{*}{66,33} \\
\hline & 2 & 100 & 1,588 & 36 & 65 & \\
\hline & 3 & 100 & 1,588 & 42 & 65 & \\
\hline \multirow{3}{*}{$\begin{array}{c}800^{\circ} \mathrm{Cl} \\
60 \text { menit }\end{array}$} & 1 & 100 & 1,588 & 40 & 65 & \multirow{3}{*}{66,67} \\
\hline & 2 & 100 & 1,588 & 38 & 66 & \\
\hline & 3 & 100 & 1,588 & 43 & 69 & \\
\hline \multirow{3}{*}{$\begin{array}{c}800^{\circ} \mathrm{Cl} \\
75 \text { menit }\end{array}$} & 1 & 100 & 1,588 & 39 & 65 & \multirow{3}{*}{69,67} \\
\hline & 2 & 100 & 1,588 & 47 & 73 & \\
\hline & 3 & 100 & 1,588 & 44 & 71 & \\
\hline
\end{tabular}

\subsection{Pembahasan}

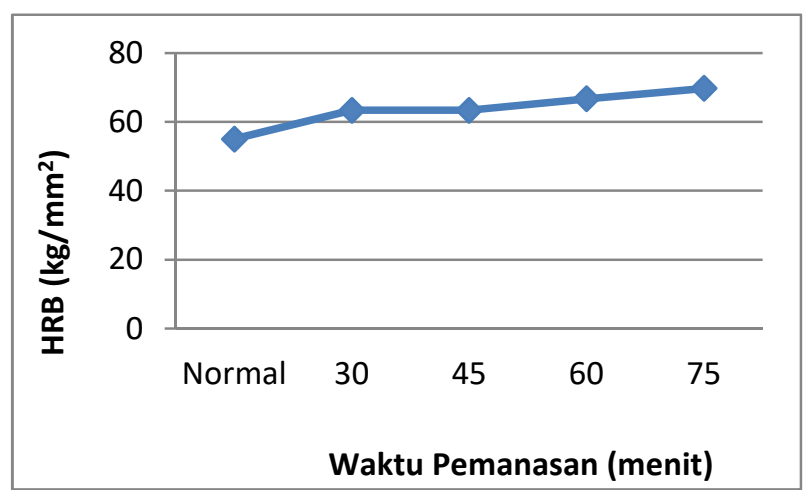

Grafik 4.1. Pengaruh Waktu Perlakuan Panas

terhadap Kekerasan Baja Karbon Rendah melalui Media Pendingin Air Garam

Pada grafik di atas diperoleh hasil penelitian untuk pemanasan baja karbon rendah dengan temperatur $800^{\circ} \mathrm{C}$ dengan variasi waktu penahanan makadiperoleh nilai kekerasan dari setiap perlakuan panas dengan penahanaan normal sebesar $55,00 \mathrm{~kg} / \mathrm{mm}^{2}$, penahanan selama 30 menit sebesar $63,33 \mathrm{~kg} / \mathrm{mm}^{2}$, penahanan selama 45 menit sebesar $66,33 \mathrm{~kg} / \mathrm{mm}^{2}$, penahanan selama 60 menit sebesar $66,67 \mathrm{~kg} / \mathrm{mm}^{2}$, dan penahanan selama 75 menit sebesar $69,67 \mathrm{~kg} / \mathrm{mm}^{2}$.

Pada waktu penahanan selama beberapa menit, struktur mikro yang terjadi pada baja karbon rendah mengalami pembentukan molekul yang besar sehingga apabila diberikan lagi waktu penahanan pada baja molekul-molekul struktur kristal dari baja tersebut akan semakin renggang dan menjadi besar sehingga kekerasan yang dimiliki dari baja tersebut akan menjadi tinggi akibat dari waktu penahanan yang di berikan. 


\section{KESIMPULAN}

Dari variasi waktu perlakukan panas 30 menit, 45 menit, 60 menit dan 75 menit dengan media pendingin air garam, diperoleh nilai kekerasan tertinggi pada waktu pemanasan 75 menit yaitu $69,67 \mathrm{~kg} / \mathrm{mm}^{2}$. Semakin lama waktu perlakuan panas, maka semakin tinggi nilai kekerasannya.

\section{REFERENSI}

Amstedd. B.H. Penterjemah Sriati Djaprie. 1981. Teknologi Mekanik. Jakarta: Erlangga.

Breuner, B.J.M, Pengetahuan Bahan, Bhatara Aksara.

Daryanto. 1985. Pengetahuan Teknik Metalurgi. Bandung: Trasito

Efendi, S.2009. Pengaruh Perbedaan Waktu Penahanan Suhu Stabil Terhadap Kekerasan Logam. Politeknik Negeri Sriwijaya. Pdf.

George E. Diater, Jakarta 1988. Metalurgi Mekanik, Jilit 2, Edisi Ketiga, Erlangga.

Hasan, Iqbal. 1999.Pokok-pokok Materi. Jakarta. Bumi Aksara.

Klasifikasi Logam. http://romzneverdie.files.wordpress.com/2010/12/klasifikasi-logam.jpg. Diakses tanggal 3 November 2014.

Lowrance H. Van Vlack (Sriati Djafrie). 1992.Ilmu dan Teknologi Bahan (Ilmu Logam dan Bukan Logam) edisi kelima, Erlangga.

Necly, Jhon E. 1984. Practikal Metalurgi and Material of Industry, New York. Jhon Wiley and Sons, inc

Pengujian Kekerasan Rockwell.

http://cybersatu.blogspot.com/2011/05/pengujian-kekerasan-rockwell.html. Diakses tanggal $\underline{3 \text { November } 2014 .}$

R.N Wright. 1980. Wine Technologi American Iron.

Sriati, Djafri. 1992. Ilmu dan Teknologi Bahan, Jakarta : Erlangga.

Suherman,W.1998.Prinsip PerlakuanPanas,ITS,Surabaya.

Surdia, Tata \& Shindroku Saito. 1999. Pengetahuan Bahan Teknik. Jakarta : PT. Pradnya Paramita.

Syuaib, M. Faiz. 2006. Kuliah Perbengkelan Modul Penuntun. 